$05,11,13$

\title{
Распространение поверхностной магнитоупругой волны в ферромагнетике в области ориентационного фазового перехода
}

\author{
(C) И.В. Мальцев ${ }^{1}$, И.В. Бычков ${ }^{1,3}$, Д.А. Кузьмин ${ }^{1,3}$, В.Г. Шавров ${ }^{2}$ \\ 1 Челябинский государственный университет, \\ Челябинск, Россия \\ ${ }^{2}$ Институт радиотехники и электроники им. В.А. Котельникова РАН, \\ Москва, Россия \\ ${ }^{3}$ Южно-Уральский государственный университет, \\ Челябинск, Россия \\ E-mail: malts_iv@mail.ru
}

Поступила в Редакцию 30 декабря 2019 г.

В окончательной редакции 30 декабря 2019 г.

Принята к публикации 10 января 2020 г.

\begin{abstract}
Исследованы зависимости групповой скорости и затухания магнитоупругой поверхностной волны от частоты при различных величинах внешнего магнитного поля и различных углах распространения. Всплески групповой скорости приходятся на частоты, на которых обнаруживаются пики затухания поверхностной волны. Также было исследовано поведение поверхностной магнитоупругой волны вблизи ориентационного фазового перехода. В точке фазового перехода наблюдается изменение групповой скорости на $1 \%$. А зависимости величины затухания вдоль поверхности при различных углах распространения указывают на невзаимную природу волны. Все зависимости в данной работе получены с помощью компьютерных вычислений, параметры ферромагнетика взяты типичные для железо-иттриевого граната.
\end{abstract}

Ключевые слова: ферромагнетик, магнитоупругость, фазовый переход, поверхностная волна.

DOI: $10.21883 /$ FTT.2020.06.49336.36M

\section{1. Введение}

Хорошо известно, что акустические волны в кристалле ферромагнетика могут взаимодействовать с магнитной подсистемой, создавая тем самым магнитоупругую волну, являющуюся комбинацией волны напряжений и спиновой волны. Первые исследования по взаимодействию магнитной и упругой подсистем магнетиков были проведены в работах Турова, Ирхина [1], Ахиезера, Барьяхтара, Пелетминского [2,4], Киттеля [3]. В них было предсказано существование связанных магнитоупругих волн в ферро- и антиферромагнетиках. Эти работы явились основополагающими при зарождении новой области физики магнитоупорядоченных веществ магнитоакустике. В настоящее время магнитоакустика находит широкое применение в электронике и технике СВЧ [5-7].

Поверхностную магнитоупругую волну создает взаимодействие упругих волн на поверхности кристалла с объемными и поверхностными спиновыми волнами. Исследованиям распространения поверхностных магнитоупругих волн посвящено достаточно много теоретических и экспериментальных работ, обзор [8] и ссылки в нем. Известно, что магнитоупругое взаимодействие является относительно слабым, но в окрестности ориентационного фазового перехода оно может оказаться достаточно большим и существенно повлиять на динамические и статические свойства магнетиков. Это связано с компенсацией поля анизотропии кристалла внешним магнитным полем. В настоящей работе мы исследуем зависимости групповой скорости и относительное затухание поверхностной магнитоупругой волны кубического ферромагнетика от частоты и внешнего магнитного поля, вдали и вблизи ориентационного фазового перехода.

\section{2. Постановка задачи}

Геометрия задачи показана на рис. 1.

Кристалл занимает полупространство $y>0$. Внешнее постоянное магнитное поле $\mathbf{H}_{0}$ и намагниченность М направлены по оси $z$ параллельно поверхности. Ось $z$ направлена вдоль кристаллографической оси (001).

Волна распространяется с частотой $\omega$ и волновым вектором $\mathbf{Q}_{\|}$(параллельно поверхности), под углом $\theta$ к оси $x$.

Термодинамический потенциал магнетика может быть представлен в виде суммы трех слагаемых

$$
F=F_{e}+F_{m e}+F_{m} .
$$

где $F_{m}-$ магнитная, $F_{e}-$ упругая и $F_{m e}-$ магнитоупругая энергии [9]. 


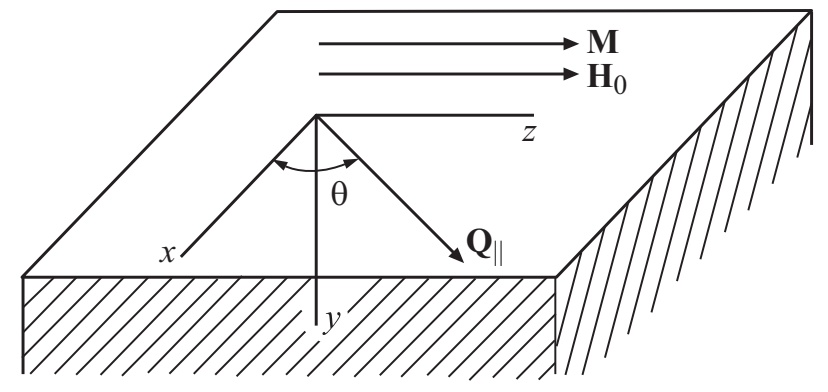

Рис. 1. Геометрия задачи. Намагниченность ферромагнетика и приложенное внешнее магнитное поле параллельны поверхности.

Для получения уравнений движения магнитной подсистемы используем уравнение Ландау с учетом релаксации в форме Блоха

$$
\frac{d \mathbf{M}}{d t}=g\left[\mathbf{M}, \mathbf{H}_{e f f}\right]-\frac{\mathbf{M}}{\tau},
$$

где $g$ - гиромагнитное отношение, $\tau$ - время релаксации намагниченности, $\mathbf{H}_{e f f}-$ эффективное магнитное поле внутри ферромагнетика. Уравнение движения упругой среды записывается как

$$
\rho \frac{\partial^{2} u_{i}}{\partial t^{2}}=\frac{\partial^{2} \sigma_{i k}}{\partial x_{k}}=\frac{1+\delta_{i k}}{2} \frac{\partial}{\partial x_{k}} \frac{\partial F}{\partial u_{i k}},
$$

где $\rho-$ плотность кристалла, $\sigma_{i k}-$ тензор напряжений, $\delta_{i k}$ - символ Кронекера.

Решения уравнений движения будем искать в виде поверхностной волны, затухающей по оси $y$, т.е.

$$
A=A_{0} e^{-\alpha y} e^{-i\left(\omega t-Q_{x} x-Q_{z} z\right)},
$$

где $A-$ компоненты намагниченности, упругих смещений и поля размагничивания.

Чтобы получить поверхностную магнитоупругую волну, к объемным уравнениям следует применить граничные условия. Граничные условия включают в себя отсутствие напряжений $\sigma_{i k}=0$ и равенство нулю производной вектора намагниченности $\partial \mathbf{M} / \partial y=0$ на поверхности магнетика.

Получить аналитические выражения для закона дисперсии такой системы не представляется возможным из-за большого количества динамических переменных, поэтому были применены численные методы решения аналогичные методике, описанной в работе [10].

Упругие, магнитные и магнитоупругие постоянные ферромагнетика используемые при вычислениях, типичны для железоиттриевого граната: $C_{l}=7.21 \cdot 10^{5} \mathrm{~cm} / \mathrm{s}$, $\rho=5.17 \mathrm{~g} / \mathrm{cm}^{3}, \quad 4 \pi M_{s}=3500 \mathrm{G}, \quad \tau=0.01 / \omega_{H}, \quad C_{t}=$ $=3.85 \cdot 10^{5} \mathrm{~cm} / \mathrm{s}, b_{1}=1.3 \cdot 10^{7} \mathrm{erg} / \mathrm{cm}^{3}, b_{1}=6.4 \cdot 10^{6} \mathrm{erg} / \mathrm{cm}^{3}$, $g=1.759 \cdot 10^{7} \mathrm{rad} / \mathrm{s} \cdot \mathrm{G}, \quad D=4.55 \cdot 10^{-9} \mathrm{~cm}^{2} \cdot \mathrm{G}, \quad K_{l}=$ $=-1 \cdot 10^{6} \mathrm{erg} / \mathrm{cm}^{3}$.

Магнитную анизотропию можно описать с помощью первой константы кубической анизотропии $K_{l}<0$. В таком случае, при увеличении внешнего магнитного поля до поля анизотропии НА, в ферромагнетике будет иметь место ОФП 2-го рода из коллинеарного состояния в угловую фазу с намагниченностью в плоскости типа (110) [9]. Закон дисперсии спиновых волн при учете магнитоупругой связи будет выглядеть следующим образом:

$$
\begin{gathered}
\omega_{s k}=g D\left(\mathbf{Q}_{\|}^{2}-\alpha^{2}\right)+\omega_{s o}+\omega_{m e}, \\
\omega_{s o}=\omega_{A}+\omega_{H}=g\left(2 K_{l} / M_{s}+\mathbf{H}_{0}\right), \quad \omega_{m r}=g b_{l}^{2} / M_{s} \rho C_{t}^{2},
\end{gathered}
$$

где $D$ - постоянная неоднородного обмена.

При выбранных постоянных ферромагнетика ориентационный фазовый переход будет наблюдаться при напряженности внешнего магнитного поля $H_{0}=7180 \mathrm{Oe}$.

\section{3. Результаты}

На рис. 2 представлена зависимость групповой скорости $V_{g r}$ и относительное затухание магнитоупругой волны $C_{t} \operatorname{Im} Q_{\|} / \omega$ от частоты вдали и вблизи фазового перехода. На рисунках отчетливо видны всплески групповой скорости, причем соответствующие им частоты отличаются при различных величинах внешнего магнитного поля $H_{0}$. Отметим, что при приближении к величине $H_{0}$, соответствующей фазовому переходу, пики затухания увеличиваются по амплитуде.
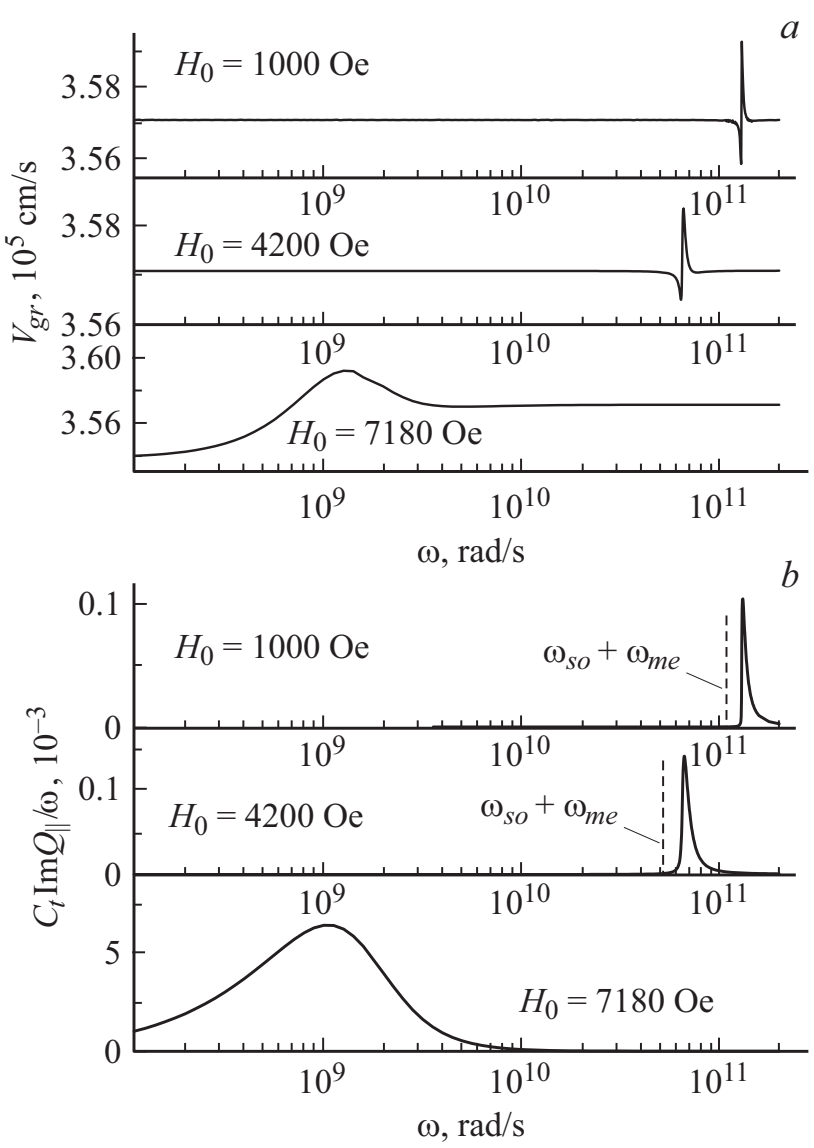

Рис. 2. Зависимости групповой скорости $V_{g r}$ от $\omega(a)$ и относительного затухания магнитоупругой волны $C_{t} \operatorname{Im} Q_{\|} / \omega$ от $\omega(b)$ при различных $H_{0}$. 

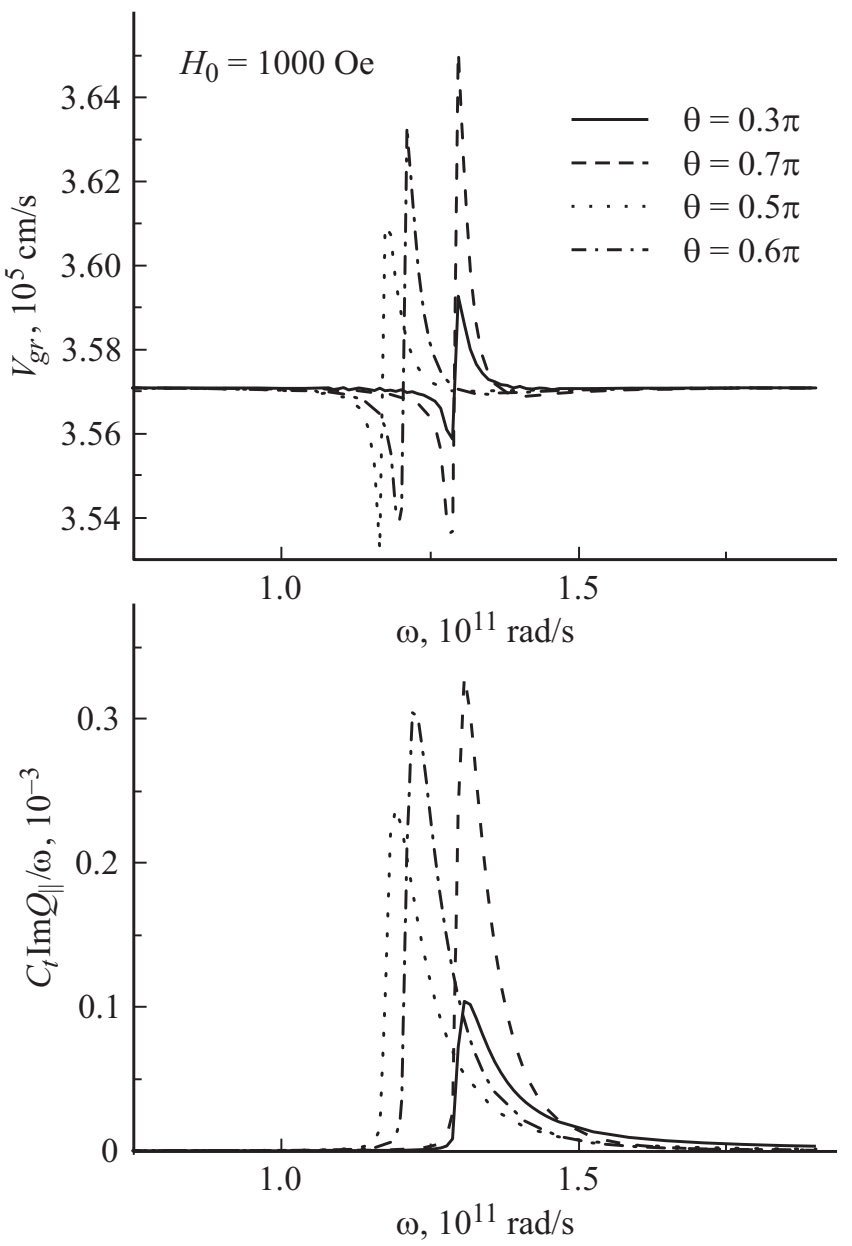

Рис. 3. Зависимости групповой скорости $V_{g r}$ и относительного затухания магнитоупругой волны $C_{t} \operatorname{Im} Q_{\|} / \omega$ от $\omega$ при различных углах $\theta . H_{0}=1000$ Oе.

Пики затухания приходятся на те же частоты, на которых обнаруживаются всплески групповой скорости. Это говорит о том, что в момент изменения групповой скорости происходит поглощение поверхностной волн. Энергия поверхностной волны переходит в энергию объемных магнитоупругих волн, причем в точке ОФП сильное поглощение происходит на гораздо большем диапазоне частот, чем вдали от него. Заметим, что вблизи ОФП, при $H_{0}=7180 \mathrm{Oe}$, изменение групповой скорости $V_{g r}$ достигает $1 \%$ от абсолютной величины, что существенно больше, чем при других значениях $H_{0}$.

В работе [11] было показано, что при отсутствии обмена $(D=0)$ пик поглощения ожидается на частоте $\omega_{H}$. В нашем случае закон дисперсии спиновых волн имеет форму (5), а значит, пик затухания при отсутствии обмена следует ожидать при частоте

$$
\omega_{s o}+\omega_{m e}=g\left(\frac{b_{l}^{2}}{M_{s} \rho C_{t}^{2}}+\frac{2 K_{l}}{M_{s}}+H_{0}\right),
$$

а в точке ОФП при частоте $\omega_{m e}$. Таким образом, частоты $\omega_{s o}+\omega_{m e}$ будут равны $1.08 \cdot 10^{11}, 5.24 \cdot 10^{10}$ и $2.77 \cdot 10^{7} \mathrm{rad} / \mathrm{s}$ при полях $H_{0}=1000 \mathrm{Oe}, 4200 \mathrm{Oe}$ и 7180 Ое соответственно. При фазовом переходе $\left(H_{0}=7180 \mathrm{Oe}\right)$ наблюдается сильное отклонение пика от частоты $\omega_{s o}+\omega_{m e}$.

На рис. 3 представлены зависимости групповой скорости и относительного затухания магнитоупругой волны при внешнем магнитном поле $H_{0}=1000$ Ое и различных углах распространения. На рисунке видно, что при углах $\theta=0.3 \pi$ и $\theta=0.7 \pi$ пики затухания приходятся на одни и те же частоты, однако величина этих пиков существенно отличается. Это говорит о невзаимной природе волны: волна, движущаяся справа налево через магнитное поле сильнее затухает, чем волна, движущаяся слева направо. Угол $\theta=0.5 \pi$ соответствует направлению внешнего поля $H_{0}$. Мы видим, что в этом случае пик затухания находится несколько ближе к значению $\omega_{s o}+\omega_{m e}$, чем при других углах $\theta$.

\section{4. Заключение}

С помощью компьютерных вычислений было исследовано распространение магнитоупругой поверхностной волны на полубесконечном кристалле в присутствии внешнего магнитного поля. Получены зависимости относительного затухания магнитоупругой волны от частоты. Пики затухания близки к частотам $g\left(H_{0}+2 K_{l} / M_{s}\right)+\omega_{\text {me}}$, определяемые суммарной анизотропией и магнитоупругим взаимодействием. Отклонение от этих частот в большой степени обусловлено наличием обменного взаимодействия. Также можно заметить, что при углах распространения, близких к $0.5 \pi$, т.е. параллельно магнитному полю, это отклонение уменьшается. Вблизи ориентационного фазового перехода, когда суммарная анизотропия равна 0, пик затухания и изменение групповой скорости намного больше, чем вдали от него. Также была показана невзаимная природа магнитоупругой поверхностной волны.

\section{Финансирование работы}

Работа выполнена при поддержке грантов Российского Фонда Фундаментальных Исследований № 16-29-14045, № 17-57-150001, № 19-07-00246 и при поддержке Правительства РФ (Постановление № 211 от 16.03.2013г.), соглашение № 02.А03.21.0011.

\section{Конфликт интересов}

Авторы заявляют, что у них нет конфликта интересов.

\section{Список литературы}

[1] Е.А. Туров, Ю.П. Ирхин. ФММ 3, 1, 15 (1956).

[2] А.И. Ахиезер, В.Г. Барьяхтар, С.В. Пелетминский. ЖЭТФ 35, 1, 228 (1958).

[3] C. Kittel. Phys. Rev. 110, 4, 836 (1958).

[4] С.В. Пелетминский. ЖЭТФ 37, 2, 452 (1959). 
[5] К.П. Белов. Магнитострикционные явления и их технические приложения. Наука, М. (1987).

[6] Б.А. Голдин, Л.Н. Котов, Л.К. Зарембо, С.Н. Карпачев. Спин-фононные взаимодействия в кристаллах (ферритах). Наука, М.-Л. (1991).

[7] Дж. Такер, В. Рэмптон. Гиперзвук в физике твердого тела. Мир, М. (1975).

[8] Ю.В. Гуляев, И.Е. Дикштейн, В.Г. Шавров. УФН 40, 701 (1997).

[9] И.В. Бычков, Д.А. Кузьмин, В.Д. Бучельников, В.Г. Шавров. Влияние взаимодействия подсистем на динамические свойства магнетиков. Физматлит, М. (2016). 176 с.

[10] R.E. Camley, R.Q. Scott. Phys. Rev. B 17, 11, 4327 (1978).

[11] R.Q. Scott, D.L. Mills. Solid State Commun. 18, 849 (1976).

Редактор Т.Н. Василевскал 